\title{
5G Technology: A New Step to IoT Platform
}

\author{
S.I. Yusifov, N.A. Ragimova, V.H. Abdullayev*, \& Z.B. Imanova \\ Azerbaijan State Oil and Industry University, Baku, Azerbaijan
}

\begin{abstract}
The article is dedicated to the study of $5 \mathrm{G}$ technology, the name of which we have heard a lot recently. This technology is one of the most talked about technologies of recent times. 5G has entered our lives as the latest and fastest version of mobile networks. Here's a look at how 5G technology came into our lives, how it has captured the attention of users, and finally, what they think about the technology. In addition, what areas are affected by this technology, in particular, its impact on the IoT field has been studied and key theoretical information has been provided.
\end{abstract}

(C) 2020 Author(s). All rights reserved.

Keywords: 5G, IoT, 5G technology, Internet of Things, Information Technology, COVID-19

\section{Introduction}

Everyone interested in technology had heard the term 5G technology from the very beginning, when it was first designed. It was said that from 2019, such technology will be available to people. However, this technology has achieved to make a name for itself, especially since the beginning of 2020, not only by those who are interested in technology, but almost by most people around the world. Of course, the reason for the rapid spread of this technology is not only that it is a leading technological step, but also the spread of the Covid 19 virus, which has emerged as a major threat to the world since the beginning of 2020. There was even a time when people began to see this technology as the cause of the spread of the virus. And most of the peoples of the world were against the use of this technology. But how true are these ideas ? So is this technology really likely to spread the virus ? Was 5G technology a weapon created under the name of technology? All these questions began to think people after the spread of the Covid 19 virus and posed a great threat to the world.

\subsection{G Technology}

In telecommunications, $5 \mathrm{G}$ is the fifth generation technology standard for mobile networks, the planned successor to $4 \mathrm{G}$ networks that provide connectivity to most current mobile phones. In simpler terms, $5 \mathrm{G}$ is a 5 th generation mobile network.

It is a new global wireless standard after $1 \mathrm{G}, 2 \mathrm{G}, 3 \mathrm{G}$ and $4 \mathrm{G}$ networks. $5 \mathrm{G}$ allows a new network designed to connect almost anyone and everything, including machines, objects and devices. This statement reminds us of another technological standard. Undoubtedly, this is IoT technology (Qualcomm, n.d.; Nordrum, \& Clark, 2017).

\footnotetext{
* Corresponding author.

E-mail address: abdulvugar@mail.ru (V.H. Abdullayev)
}

JINAV: Journal of Information and Visualization is licensed under an Attribution-NonCommercial-ShareAlike 4.0 International (CC BY-NC-SA 4.0) 
The question is, does anyone own 5G technology? This may sound a bit different, but no company or individual owns 5G technology, but there are several companies, that contribute to the implementation of 5G within the mobile ecosystem. For example, Qualcomm has played a major role in the development of many key technologies that will drive the industry and make it the next wireless standard, 5G.

The main purpose of the mobile network, that is, the creation and updating of mobile technologies over time, is undoubtedly to help users get the information they want very quickly.

We can mention 3 types of 5G: Low band 5G, Medium band 5G, High band 5G. (Waring, 2018)

Low band 5G operates at frequencies below $2 \mathrm{GHz}$. These are the oldest mobile and TV frequencies. They go long distances, but there are no very wide channels, and most of these channels are use for 4G. Thus, low-bandwidth 5G is slow. Low band $5 \mathrm{G}$ channels range from $5 \mathrm{MHz}$ (for AT\&T) to $15 \mathrm{MHz}$ (for T-Mobile). As you can see, it is no bigger than $4 \mathrm{G}$.

Mid-band 5G is in the range of 2-10 GHz. Covers most of the current mobile and Wi-Fi frequencies and slightly above them. These networks often have a distance of about half a mile from the towers, so in most countries they are the working networks with the most $5 \mathrm{G}$ traffic.

High bandwidth 5G or millimeter wave is really a new step. So far, these are mainly airwaves in the range of 20-100 GHz. These airwaves have not been use for consumer applications before. They are use over very short distances; so the tests show a distance of about 800 feet from the towers. But there is a lot of unused spectrum, which means a very high speed of up to $800 \mathrm{MHz}$ at a time.

So why was $4 \mathrm{G}$ updated to $5 \mathrm{G}$ ? With $5 \mathrm{G}$, mobile internet speeds increase 20 times compared to $4 \mathrm{G}$. Although $4 \mathrm{G}$ promised 1GB per second, in practice it did not achieve this. For 5G, it is project at 20 GB per second.

\section{The question is, is $5 G$ so fast?}

The answer to this question depends on where you live, which service operator you use, and so on. will vary according to. But compared to the current speeds, the simple answer to the problem: yes, it is very fast. Qualcomm, for example, claims that its tests reach 4.5 gigabits per second, but this is the highest speed achieved. The average speed is say to be 1.4 gigabytes per second, which is 20 times higher than the fastest $4 \mathrm{G}$ communication. Downloading a high quality movie will take only 15 seconds at average speed. If you reach a speed of 4 or 5 gigabits, you will have a connection power 100 times faster than now, and the 'download' button will be change to the 'play' button, which means that your touch will start playing the movie at the same time. It does not take a minute to download all the seasons and series in high quality. Delays in loading websites will also be sharply reduce. To access a site, information must go through various service providers and physical centers. Today, delays of 50 to 100 milliseconds are consider normal. With 5G, which offers new technologies in this area, the delay time will be reduce to a few milliseconds.

\section{What will $5 G$ change?}

These speeds in the areas of communication and latency are expect to open up revolutionary developments in many areas, especially in virtual reality applications. As devices become lighter and more mobile, virtual reality and augmented reality applications can be consider a part of everyday life. $+5 \mathrm{G}$ will change lives in many ways, from social life to business life, from education to entertainment, advertising applications to new workplaces, from advertising to commerce. For example, when you watch a football match in a stadium, when you look at the field with your phone's camera and augmented reality glasses, you can see all the information you want to see about the game and the players without immediately delaying or waiting. Depending on how small the devices are, perhaps the referees and the players themselves will benefit from this technology (Qualcomm, n.d.).

$5 \mathrm{G}$ is also driving global growth. We can note the following:

- \$13.2 trillion in global economic output

- 22.3 million new jobs 


\section{- \$2.1 trillion GDP growth}

This is another question, that makes people think. How will 5G technology affect me, ie how will 5G affect consumers?

5G is specifically design to do a variety of things that can change our lives by providing faster download speeds, lower latency, more capacity and connectivity for billions of devices in virtual reality (VR), artificial intelligence (AI), IoT and other areas.

5G also brings the concept of the Internet of Things. Even the smallest devices in the house are expect to be able to connect to the Internet. Refrigerators, watches, televisions, air conditioners and other items are expect to be able to connect at high internet speeds.

In short, $5 \mathrm{G}$ is a new technology that will change our lives.

\section{Advantages and Disadvantages of $5 G$ Technology}

The most important advantage of $5 \mathrm{G}$ is high speed. It is expected to be more than $1 \mathrm{~Gb} / \mathrm{s}$, with significant improvements in download speeds. Considering that we manage a lot of work in our daily lives via the Internet, it is obvious how profitable this fast technology is.

5G technology provides a wider coverage. With this feature, it is expected to solve the coverage problems that often occur in rural areas. It is expected that rural enterprises will be able to compete in the digital market and strengthen the region's economy.

One of the biggest problems with smartphones is the short battery life. The goal is to reduce the power consumption of mobile devices with $5 \mathrm{G}$ and extend battery life by 10 years. In addition, no matter how unusual it sounds, it is thought that even charging phones once a month will suffice.

All of these are the benefits that $5 \mathrm{G}$ technology promises to its users.

But as with any technological innovation, 5G technology has its own disadvantages.

The spread of 5G technology takes a long time, because this technology is supported only by the latest mobile devices. In addition, as many new infrastructures need to be created, countries need to allocate significant budgets to this issue.

5G technology is thought to be vulnerable to cyber attacks due to security concerns. Because it is a software-based network, there are concerns about high software risks. It is stated that vulnerabilities that may occur during the development of the program can threaten the entire network (Ahmad, et.al., 2018).

And finally, the biggest and most thought-provoking disadvantage is the fact that it is harmful to the human body. According to Salets, " $5 \mathrm{G}$ requires the installation of hundreds of thousands of new antennas and base stations. This puts people at risk of radiation. Many people are concerned about the long-term effects of this on their health. This “ is $5 \mathrm{G}$ harmful ? " brings the question to mind. (Aktan \& Beswick, 2020).

In this regard, some countries have suggested the abolition of 5G technology. Last year, for example, the Polish government signed a global call for the abolition of 5G technology. The report said:

"Polish Prime Minister Mateusz Morawiecki has joined an international call to suspend the use of 5G technology and signed a document.

According to a study of 2,000 leading scientists and 1,400 doctors, 5G technology is dangerous for the human body. There is also a danger to animals and plants.

No experiments were conducted before the introduction of 5G. Although these technologies are installed higher than $3 \mathrm{G}$ and $4 \mathrm{G}$, the damage of its electromagnetic particles is greater. These particles cause cancer, genetic disorders, stress, changes in the reproductive system, and memory problems in humans (Biktim, 2020). 
In particular, the idea that $5 \mathrm{G}$ technology will affect the human body has come to the fore since the beginning of this year, with the idea that it is associated with the coronavirus. Thus, it was claimed that the $60 \mathrm{Ghz}$ frequency used by $5 \mathrm{G}$ was absorbed by oxygen molecules, which prevented the uptake of oxygen by hemoglobin and increased the problem of respiratory failure in Covid-19 patients. But how true is this idea ?

However, there is still no scientific explanation for these theories. These are just a few baseless ideas put forward by people. So, after this news spread, people took these theories very seriously and even a group of people attacked to base stations. However, many officials have repeatedly stated that there is no connection between $5 \mathrm{G}$ technology and Covid-19.

Currently, the number of 5G technology base stations is higher in South Korea, the United States and China. Undoubtedly, the People's Republic of China is one of the countries that shows that such theories are unfounded. It is even noted that China uses 5G technology, especially in the fight against coronavirus (Collela, n.d.).

We have mentioned information about $5 \mathrm{G}$ and its advantages and disadvantages. Now let's talk about what areas and how this technology will affect.

\section{Areas Affected by 5G Technology}

Simply put, 5G technology will have a unique impact to all areas where the Internet is used. And if we consider that the number of areas where the Internet is not used at present is very small. This means that $5 \mathrm{G}$ technology will make a big difference in our lives. That is, 5G technology covers everything from people's daily lives, production, medicine, national economy, education and so on. will have a major impact on areas such as, most of which will be beneficial. Undoubtedly, the technology closest to people's daily lives is IoT technology. That's why let's take a closer look at how $5 \mathrm{G}$ will affect IoT.

Existing 4G networks have been widely used in the Internet of Things (IoT) and are constantly evolving to meet the needs of future Internet of Things (IoT) applications. It will be able to strengthen 5G networks, mobile operations, IoT security and network problems. Today's IoT is expected to expand (Wang, et.al, 2018). 5G will promote innovation in many industries and provide a platform that allows new technologies such as IoT to become an integral part of our economy and lifestyle.

5G itself will affect to IoT technology and High Tech (Wang, et.al, 2018). 5G is the basis for realizing the full potential of IoT. Although 5G was set up for commercial use in 2020, the industry is already working to develop new global standards and products up to 5G to benefit industries everywhere. Ericsson said the latest EU Mobility Report will have 550 million 5G subscribers by 2022, making Asia the second fastest growing region in the Pacific.

$5 \mathrm{G}$ promises us more than fast downloads; It will support smart vehicles and such as high-speed connection, very low latency and a unique combination of local coverage, as well as connected vehicles, trucks and buses and transport infrastructure. $5 \mathrm{G}$ allows us to remotely control more devices in dangerous environments, remotely control heavy machinery, thereby enhancing employee safety and even real-time network performance. At the same time, 5G promises to make remote medical care a reality and an exchange agent for the industry's future.

One of the terms that comes to mind when talking about IoT is the term smart cities. So, as 5G will affect IoT as a whole, it will also affect to Smart Cities. Smart cities can use 5G in a variety of ways to change the lives of the people who live in them primarily for greater connectivity between people and things, higher data speeds and car security, infrastructure, virtual reality (VR) and entertainment (Akpakwu, et.al., 2017).

Compared to LoRa and SigFox, for example, 5G-IoT contributes to the flourishing of a smart urban ecosystem by allowing large or small businesses to build IoT services without having to apply their own network capabilities. Many smart city services will work on 5G and promote the integration of 5G and IoT. Trend, in turn, will pose unprecedented challenges to the 5G mobile network and affect the regulatory performance of 5G (Sequeira, 2019).

With the connection at the heart of the sector transformation, 5G will play a role not only in the evolution of communication, but also in the evolution of enterprises and society as a whole. On the $5 \mathrm{G}$ path, operators will have to 
focus on new opportunities. Operators are great at combining phones, tablets, and other devices, but an increasing number of cars, meters, car sensors, and consumer electronics will require innovative business models to connect and operate at a cost-effective connection. Today, the vast majority of IoT operator's revenue comes from connectivity, but over the next 5 years, revenue will come from service activation platforms, applications and services. Operators who can refine data on IoT platforms and convert data into smart data will only be able to generate revenue that increases with the amount of data.

IoT offers operators and industries an effective platform for innovation and new ways of interacting with end customers. Key factors in success, starting a new business with the right business models, etc. will allow you to enter the market in a short time, a wide range of products, from ideas to commercial offers (Ehret \& Wirtz, 2017).

Speaking to Euronews' Emma Beswick, Bart Salaets, chief engineer at F5 Network, described how 5G would affect to our lives: Using robotic devices in different countries and cities, doctors will be able to operate on the patient there without a delay of milliseconds. Smart cities, homes, vehicles will be revolutionary for everyone (Aktan \& Beswick, 2020).

The problem with $5 \mathrm{G}$ is the various wireless technologies available today that allow IoT, such as CBRS, WiFi6, LoRa and Zigbee. Wi-Fi 6 is slightly faster and slightly lower latency than its predecessor, but the most important capability is its ability to manage 4 times more device traffic. Whether you choose $5 \mathrm{G}$ or Wi-Fi 6 , you will need new devices to realize the benefits. With so many solutions available, it will be a hybrid of many opportunities, including 5G.

$5 \mathrm{G}$ can be a great tool for a subgroup of cases using commercial IoT. This is a widespread standard with enough infrastructure behind it that can be expanded. Has the ability to adapt widely at the device and equipment level. Here are the key features that make it ideal:

- High speed (entertainment for automatic, connected and remote medical services).

- $\quad$ Low latency (mission critical industrial IoT, autonomous driving)

- Mass communication (digital factories, smart cities, wearable devices)

- $\quad$ Low energy consumption (smart buildings, fleet management)

One of the strongest uses for IoT is in manufacturing plants and digital factories. It requires 5G due to its special usage situation, large amount of data, device and low latency required. Production and industrial use are closest to commercialization, as it is clear in these usage patterns which party will pay for the IoT ecosystem and which party will benefit (the company itself).

The launch of fifth-generation mobile communications or $5 \mathrm{G}$ is great news for the IoT market. The main reason for this is that $5 \mathrm{G}$ networks have come a long way to increase the performance and reliability of these connected devices (Li, Da Xu, \& Zhao, 2018):

\section{Data transfer speed}

The commercial success of any IoT depends on how well it can interact with other IoT devices, smartphones and tablets, applications or website applications, and more. With 5G, data transfer speeds will increase significantly.

According to the report, 5G will be 10 times faster than existing LTE (Long Term Evolution) networks. This increase in speed will allow IoT devices to connect and exchange data faster than ever.

\section{Great Network Reliability}

In addition to increasing speed, 5G networks will work more reliably and create more stable connections. Having a reliable and stable network environment is critical for any IoT, especially with locks, security cameras and other monitoring systems connected to real-time updates.

Thanks to the ability of the $5 \mathrm{G}$ network to manage more connected devices, consumers will benefit from the reliability of connected devices. 
There is still a long way to go before $5 \mathrm{G}$ is fully operational. Careful execution is important here, as the commercialization of 5G and IoT can be difficult for several reasons, as shown below (Verizon, 2020):

- It's a new technology. There is no blueprint and lessons to be learned from years of deployment.

- There are multiple layers of the stack which need to come together to commercialize IoT (as shown in the table below). This causes integration challenges.

- There is a misalignment of incentives as to who invests, and who reaps the benefits from the value chain. Think of it in context of $4 \mathrm{G}$ deployment, the network was laid out by carriers, but a major beneficiary were the internet companies. For 5G, network and connectivity providers should be part of the ecosystem to monetize these new services.

Let's take a look at a few industries where 5G and IoT can make a difference together (Wang, et.al., 2018).

Self-driving cars: Sensors in automatic vehicles monitor temperature, traffic conditions, weather conditions, GPS location, etc. generates a large amount of measuring data. The production and assimilation of so much information consumes a lot of energy. Such vehicles also rely heavily on real-time data transmission to provide optimal services. However, with high-speed connectivity and low latency, the algorithms of these smart cars will be able to constantly collect all kinds of information, including critical data, when they can work to independently monitor the working condition of the car and improve future designs (Mistry, et. al., 2020).

Health care: As 5G will affect IoT, 5G will also affect to the areas affected by IoT itself. The most important of these is IoMT, ie the Internet of Medical Things technology. Rural areas and other similar remote areas that do not have adequate health facilities will benefit greatly from the IoT connection. With such a delay, world-class health services such as remote operations are becoming an opportunity (Ahad, et.al., 2020).

Logistics: 5G connectivity will allow for advanced IoT tracking sensors that can perform logistics operations. High speeds and low latency will not only allow data to be collected in real time, but also energy efficiency at all points in the supply chain and over a very long period of time. For example, the consumer can get detailed information about where the fish is caught, at what temperature it is stored during transportation and when it is delivered to retail (Wang, Yang, \& Wang, 2020).

Smart cities: $5 \mathrm{G}$ will provide a wider application in smart city initiatives, from water and waste management to traffic monitoring to advanced healthcare. As more and more sensors open the way to urban infrastructure, Smart Cities will take advantage of the new generation network. 5G will not only be able to handle the mass of data, but also integrate various intelligent systems that are constantly communicating with each other, bringing a truly connected city even closer (Minoli \& Occhiogrosso, 2019).

\section{$5 G$ and Business IoT}

5G-enabled IoT is not expected to provide only technological growth; It is also projected to help support 22 million jobs worldwide. This growth is expected to come from the digitalization of transport, agriculture, manufacturing and other physical sectors. Considering construction sites, oil fields, railways and cargo fleets: these areas will benefit greatly from the time-sensitive nature of products from ultra-fast data transmission (Rong, et.al, 2020).

5G has the potential to make progress in smart manufacturing as well as smart machines. Thinking bigger, 5G will allow IoT to perform virtually instantaneous traffic analysis, improve security and public safety, and provide remote operation.

Anyone can use 5G technology. But it should be noted that for this you need to have devices that support 5G technology. For example, smartphones running with the Snapdragon X55 or Snapdragon X60 Modem-RF System are compatible with $5 \mathrm{G}$.

There are several new mobile phones designed to support 5G, and many operators around the world support 5G wireless networks. As the 5G launch schedule expands, more smartphones and carrier subscriptions will be available for more distribution of $5 \mathrm{G}$ technology and $5 \mathrm{G}$ compliant devices. 


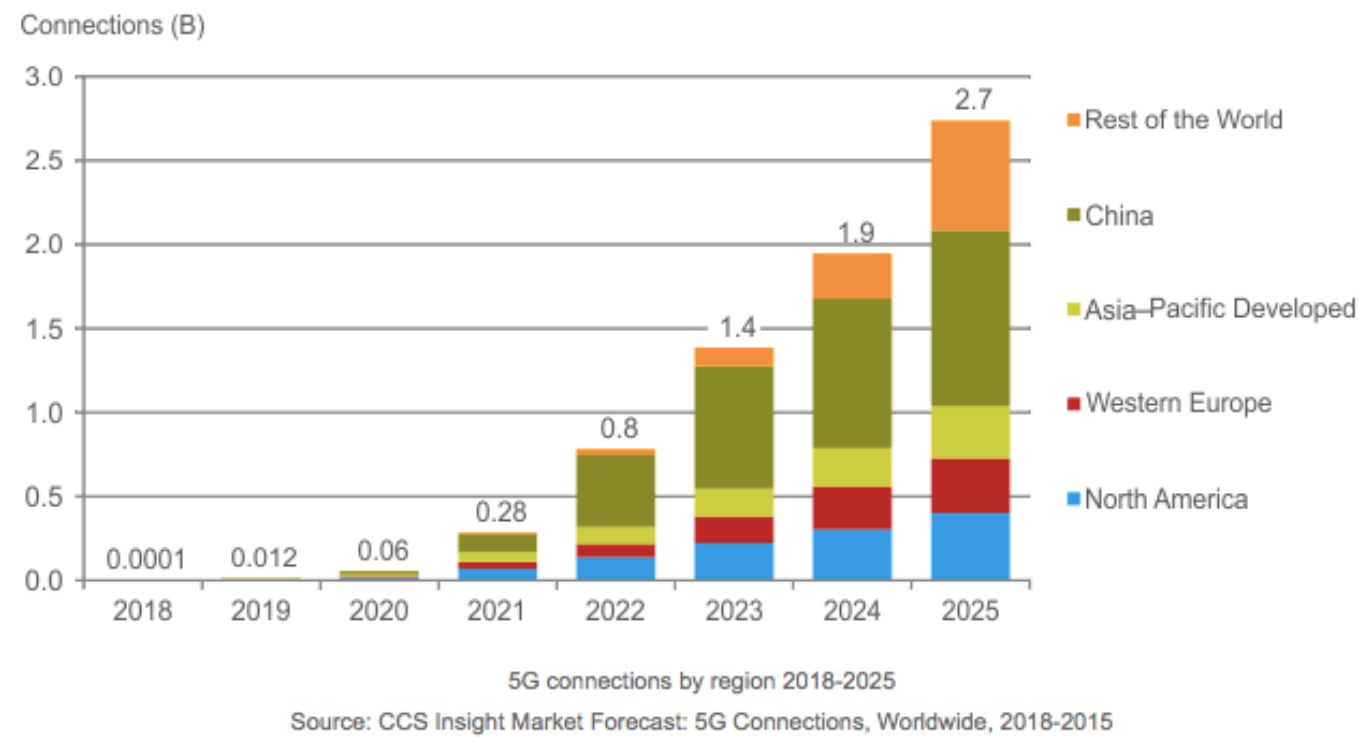

Fig. 1. 5G connections by region 2018-2025 (Waring, 2018)

After the first 5G launch in South Korea, Japan and the United States, CCS Insight estimates that China will be the fastest leader with 100 million connections in 2021 and more than 1 billion in 2025, accounting for 40\% of global 5G connections. The research company has released a short-term forecast for global 5G connectivity after the rapid development of the industry in the last six months. Thus, a total of 2.7 billion contacts are expected in 2025 . Marina Koytcheva, CCS Insight's deputy forecaster, said: "We see the first 5G smartphones coming out in 2019, but the number will be relatively small. The real boom will come in 2021 , when more than 350 million $5 \mathrm{G}$ phones will be sold worldwide. While $5 \mathrm{G}$ is already central in developing countries, emerging markets have made efforts to prepare for the transition to a new generation network. $5 \mathrm{G}$ will serve as the backbone of the fourth industrial revolution. In addition, $5 \mathrm{G}$ technology is expected to contribute $\$ 2.2$ trillion to the global economy over the next 15 years.

\section{Conclusion}

Undoubtedly, 5G technology has become the most talked about technology this year. Both with their innovations and promises, as well as with various theories. However, if we put aside some baseless theories and look at it from a technological point of view, we will eventually see that the introduction of 5G technology into our lives is a very big step for us. Now that IoT technology has become an integral part of our lives, 5G will help us use this technology more efficiently. Not only in everyday life, but in many useful areas, this technology will undoubtedly create a great revolution.

Note that with the new generation network, high-speed connection, very low latency and more coverage will be key for IoT devices. To take advantage of these developments, manufacturers must first invest in the production of 5Gcompatible devices. In addition, manufacturers must equally cover quality assurance tests to ensure that new devices and software are installed and performed as intended in different conditions.

Combined with key technologies such as cloud security, artificial intelligence and remote computing, 5G can provide significant economic benefits to businesses looking to embrace this new world. [9]

To take advantage of this opportunity, companies need to pay attention to the following steps:

- Partner internally and externally to identify use cases relevant for your company

- Embed 5G applications into upcoming product roadmaps for the next five years 
- Ensure ecosystem partners and internal teams have the right capabilities needed to build, sell, and support 5G offerings

- Build agility within operations to transition to $5 \mathrm{G}$

At last, as we know, the Internet of Things (IoT) is evolving and expanding with each passing day. The number of connected devices is expected to increase from 700 million to 3.2 billion by 2023 . And at this point, it should be noted that although there are a number of factors that lead to this growth, one of the most important will undoubtedly

be the development of $5 \mathrm{G}$ networks. $5 \mathrm{G}$ technology is a new technological era for users, for the IoT platform.

\section{References}

Ahad, A., Tahir, M., Aman Sheikh, M., Ahmed, K. I., Mughees, A., \& Numani, A. (2020). Technologies trend towards 5G network for smart health-care using IoT: A review. Sensors, 20(14), 4047.

Ahmad, I., Kumar, T., Liyanage, M., Okwuibe, J., Ylianttila, M., \& Gurtov, A. (2018). Overview of 5G security challenges and solutions. IEEE Communications Standards Magazine, 2(1), 36-43.

Akpakwu, G. A., Silva, B. J., Hancke, G. P., \& Abu-Mahfouz, A. M. (2017). A survey on 5G networks for the Internet of Things: Communication technologies and challenges. IEEE access, 6, 3619-3647.

Aktan, S. \& Beswick, E. (2020, January 14). 5 G teknolojisi nedir, hangi risklerle karşı karşıyayız, hayatımız nasıl etkilenecek? (What is 5G technology, what risks do we face, how will our lives be affected?). EuroNews. https://tr.euronews.com/2020/01/14/5g-mobil-teknolojisi-nedir-ne-kadar-hizlidir-ve-hayatimizi-nasildegistirecek-3g-4g-ve-5g

Biktim, E. (2020, May 5). Koronavirüs ile 5G arasında nasıl bir bağlantı var (What is the link between coronavirus and 5G). CNNTurk. https://www.cnnturk.com/teknoloji/koronavirus-ile-5g-arasinda-nasil-bir-baglanti-var

Collela, P. (n.d.). $5 G$ and IoT: Ushering in a new era. Ericsson. https://www.ericsson.com/en/about-us/companyfacts/ericsson-worldwide/india/authored-articles/5g-and-iot-ushering-in-a-new-era

Ehret, M., \& Wirtz, J. (2017). Unlocking value from machines: business models and the industrial internet of things. Journal of Marketing Management, 33(1-2), 111-130.

Hao, Y., Tian, D., Fortino, G., Zhang, J., \& Humar, I. (2018). Network slicing technology in a 5G wearable network. IEEE Communications Standards Magazine, 2(1), 66-71.

Li, S., Da Xu, L., \& Zhao, S. (2018). 5G Internet of Things: A survey. Journal of Industrial Information Integration, $10,1-9$.

Minoli, D., \& Occhiogrosso, B. (2019). Practical aspects for the integration of 5G networks and IoT applications in smart cities environments. Wireless Communications and Mobile Computing, 2019.

Mistry, I., Tanwar, S., Tyagi, S., \& Kumar, N. (2020). Blockchain for 5G-enabled IoT for industrial automation: A systematic review, solutions, and challenges. Mechanical Systems and Signal Processing, 135, 106382.Nordrum, A., \& Clark, K. (2017). Everything you need to know about 5G. IEEE Spectrum, 27.

Qualcomm, (n.d.). What is 5G - Everything you need to know about 5G. Retrieved Nov 9, 2020, from https://www.qualcomm.com/invention/5g/what-is-5g

Rong, B., Han, S., Kadoch, M., Chen, X., \& Jara, A. (2020). Integration of 5G networks and internet of things for future smart city. Wireless Communications and Mobile Computing, 2020, 2903525

Sequeira, N. (2019, January 11). What 5G Means for The Future of Internet of Things. 5G Technology World. https://www.5gtechnologyworld.com/what-5g-means-for-the-future-of-internet-of-things/

Verizon. (2020, April 3). 5G and IoT: The Future of 5G Communications. https://www.verizon.com/about/ourcompany $/ 5 \mathrm{~g} /$ iot-future-5g-communications 
Wang, D., Chen, D., Song, B., Guizani, N., Yu, X., \& Du, X. (2018). From IoT to 5G I-IoT: The next generation IoTbased intelligent algorithms and 5G technologies. IEEE Communications Magazine, 56(10), 114-120.

Wang, J., Yang, Z., \& Wang, Z. (2020). Intelligent Logistics Cost Control based on 5G Network and IOT Hardware System. Microprocessors and Microsystems, 103476.

Waring, J. (2018, April 10). China to take 40\% of 5G connections in 2025. Mobile World Live. https://www.mobileworldlive.com/asia/asia-news/china-to-take-40-of-5g-connections-in-2025 